\title{
Hair Tug Test: A Simple Clinical Method to Assess Skin Viability after Degloving Injury
}

\author{
Anupam Golash ${ }^{1} \quad$ Swaraj Hanspal ${ }^{1}$ \\ ${ }^{1}$ Department of Plastic Surgery, Calcutta Medical Research Institute \\ Hospital, Kolkata, West Bengal, India
}

Indian J Plast Surg 2020;53:164-165

Degloving injuries are common in road traffic accidents, especially involving the lower limb. Determining the viability of an avulsed flap is often difficult during initial assessment.

Early recognition of nonviable areas can aid in reducing the number of debridements, reducing the chances of infection and sepsis and, thus, reduce the hospital stay and aid in early recovery. Further, skin from such nonviable areas can be harvested as a skin graft for coverage of the defect before the avulsed flap becomes necrosed. ${ }^{1}$

There are few clinical methods to determine flap viability like assessment of bleeding and its color on needle prick, which may not be reliable and is subject to interobserver variability.

Other techniques, such as surface fluorometry, laser Doppler, and whole body fluorescence, involve sophisticated equipment and are not practical for assessing the viability of an acutely injured flap. They are more suited to monitor flap viability postoperatively. ${ }^{1}$

Here we describe another clinical method to determine flap viability, the hair tug test, which the authors has used
Address for correspondence Swaraj Hanspal, MS (Surgery), MCh (Plastic Surgery), Department of Plastic Surgery, Calcutta Medical Research Institute Hospital, Kolkata, West Bengal 700027, India (e-mail: swaraj.savi@gmail.com).

over the past 18 years and found it consistently reliable, and which is employed routinely at our center now.

\section{Technique}

This clinical test is done when the patient is brought in the operation theatre for initial assessment of a degloving injury and involves gentle pulling of the hair from the avulsed skin (-Figs. $\mathbf{1}$ and $\mathbf{2}$ ). If the hair is easily pulled out, including the hair follicle, the area is almost certain to undergo necrosis and thus require debridement.

If the hair cannot be easily pulled out, the portion of the skin is very likely to remain viable.

The area from which hair is easily pulled out is marked with a skin marking pen. This area is debrided or skin from this area may be taken as a skin graft to cover any raw areas (-Figs. 3 and $\mathbf{4}) .{ }^{1,2}$

The author has observed that this test is positive at the initial assessment in majority of the cases, which is within 6 to 24 hours of the trauma, long before any skin color changes are visible. The author has studied 38 cases published online April 22, 2020
DOI https://doi.org/ 10.1055/s-0040-1709961 ISSN 0970-0358.
(C)2020 Association of Plastic Surgeons of India

\section{License terms}

()ㅜ (1) $\Theta \circledast$ 


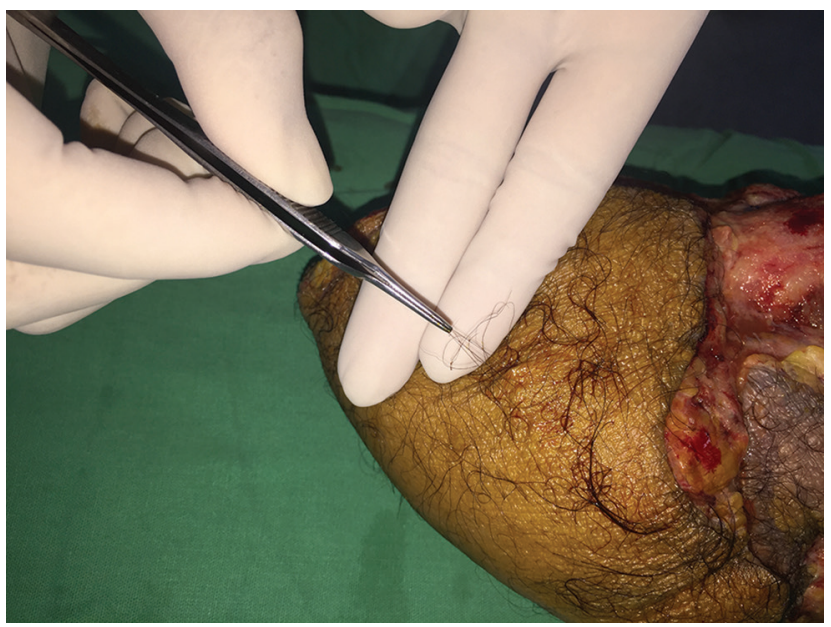

Fig. 1 Technique of gentle "tugging" on the hair using a forceps in the area to be tested.

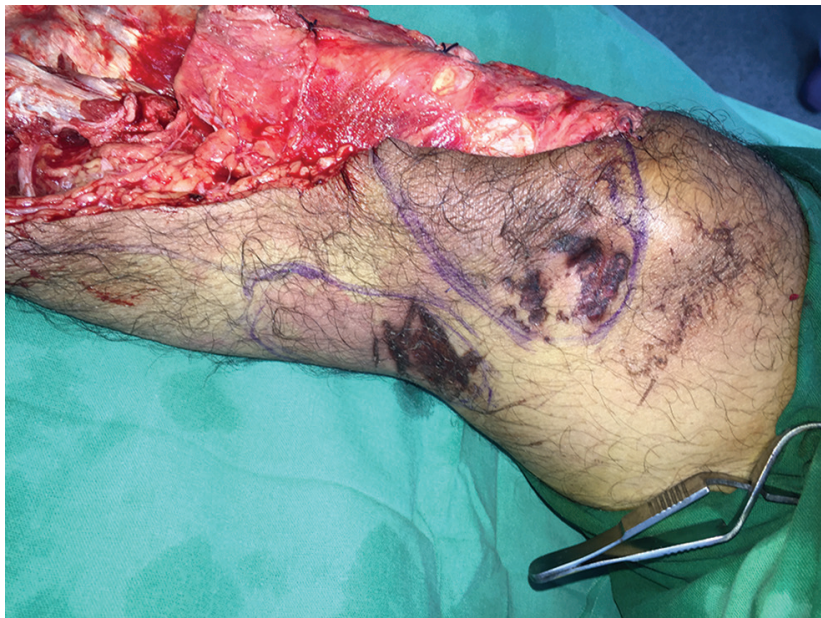

Fig. 3 The area from where hair could be pulled out easily, was marked with a skin marking pen.

of degloving injury from 2002 to 2019. In 35 cases (92.1\%), the skin from which hair could be pulled out on the first assessment (within 6-24 hours), turned necrotic in the second assessment (at 48-60 hours). In three cases (7.9\%), there was some extra necrosis beyond the marked area. But in $100 \%$ cases, the area predicted by the hair tug test turned necrotic.

\section{Conflict of Interest}

None declared.

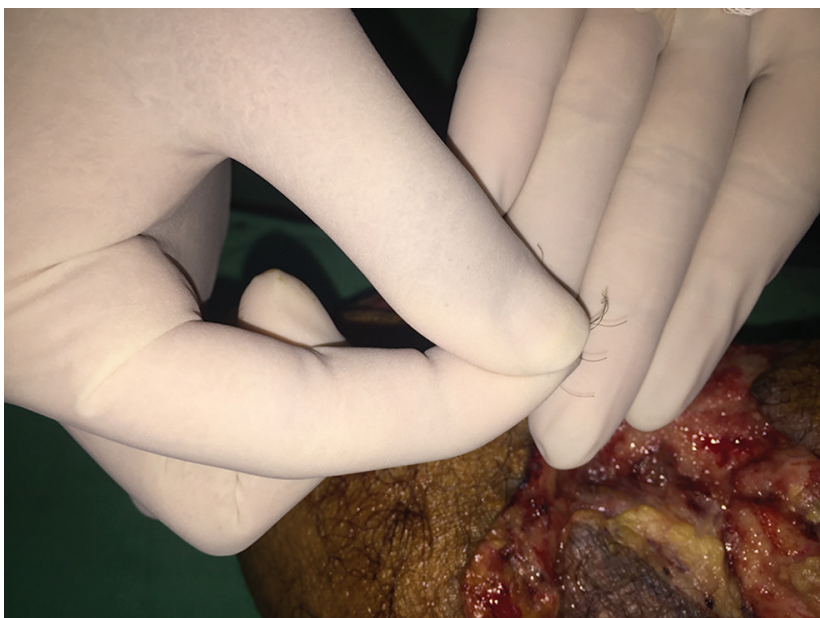

Fig. 2 In the area of impending necrosis, the hair can be pulled out easily including the hair follicle.

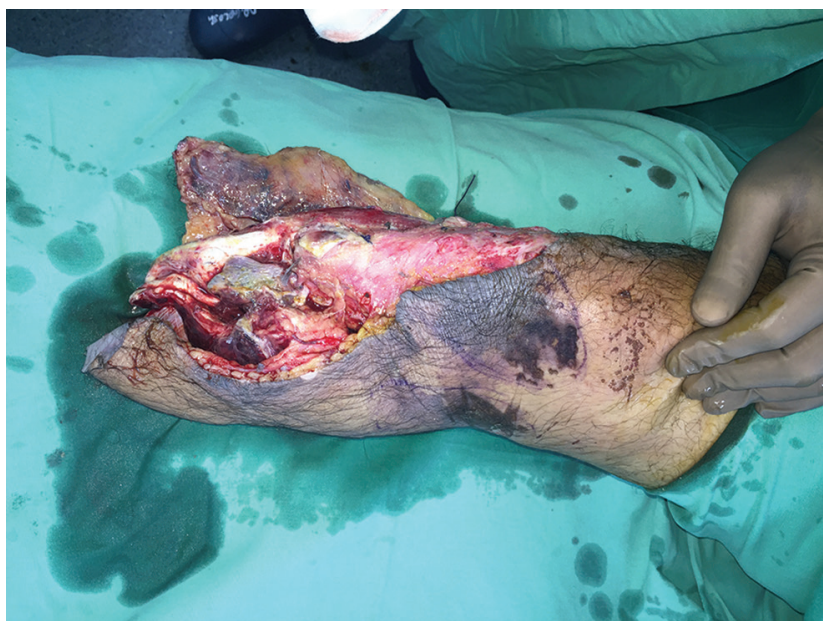

Fig. 4 At the next (second) evaluation, the skin in the marked area was found to be necrotic and was debrided.

\section{References}

1 Lim H, Han DH, Lee IJ, Park MC. A simple strategy in avulsion flap injury: prediction of flap viability using wood's lamp illumination and resurfacing with a full-thickness skin graft. Arch Plast Surg 2014;41(2):126-132

2 Zeligowski AA, Ziv I. How to harvest skin graft from the avulsed flap in degloving injuries. Ann Plast Surg 1987;19(1):89-90 